DOI: http://dx.doi.org/10.7867/1809-0354.2019v14n2s1p670-692

\title{
A LEGIÃO BRASILEIRA DE ASSISTÊNCIA E O ATENDIMENTO À INFÂNCIA NO BRASIL: O PROJETO NACIONAL DE CRECHES CASULO
}

\author{
THE BRAZILIAN LEGION OF ASSISTANCE AND CHILD CARE IN BRAZIL: THE \\ NATIONAL PROJECT OF COCOON DAYCARE
}

\section{LA LEGIÓN BRASILEÑA DE ASISTENCIA Y ATENCIÓN A LA INFANCIA EN BRASIL: EL PROYECTO NACIONAL DE GUARDERÍAS INFANTIL}

\author{
CONCEIÇÃO, Caroline Machado Cortelini \\ cmcortelini@yahoo.com.br \\ Unioeste - Universidade Estadual do Oeste do Paraná \\ https://orcid.org/0000-0002-3442-3904
}

\begin{abstract}
RESUMO Este artigo aborda o papel desempenhado pela LBA no atendimento à infância no Brasil, entre as décadas de 1970 e 1980. O texto evidencia as funções desempenhadas pela LBA nacionalmente e os desdobramentos de suas ações através do projeto nacional de Creches Casulo em um contexto específico, o município de Francisco Beltrão/PR. A História Cultural é a base epistemológica que fundamenta a análise teórica e o percurso metodológico do trabalho. Toma como documentos de análise textos políticos de abrangência nacional, documentos de abrangência local e as memórias de diversos sujeitos envolvidos no processo. Conclui que as marcas impressas pelo projeto de creches da LBA ainda hoje apresentam fortes repercussões na educação infantil nacional, vinculando as instituições de educação infantil à ideia de prestadoras de favor aos mais necessitados.
\end{abstract}

Palavras-chave: Creche. Educação infantil. Infância. Legião Brasileira de Assistência.

\begin{abstract}
This article discusses the role played by the LBA in attendance to childhood in Brazil, between the decades of 1970 and 1980. The text highlights the functions performed by the LBA nationally and the ramifications of their actions through the national project of Cocoon Daycare in a specific context, the city of Francisco Beltrão-PR. Cultural history is the epistemological basis that justifies the theoretical analysis and the methodology of the course work. Takes political texts analysis documents of national scope, spanning local documents and memories of various subjects involved in the process. Concludes that the marks printed by day care project of the LBA today feature strong repercussions on national children's education by linking early childhood institutions the idea of providing favors to the needy.
\end{abstract}

Keywords: Daycare. Early Childhood Education. Childhood. Brazilian Legion of assistance.

RESUMEN Este artículo aborda el papel desempeñado por la LBA en la atención a la infancia en Brasil, entre las décadas de 1970 y 1980. El texto pone de relieve las funciones desempeñadas por la LBA nacionalmente y los despliegues de sus acciones por medio del diseño de Guarderías Infantiles en un contexto específico, en el municipio de Francisco Beltrão/PR. La Historia Cultural es la base epistemológica que 


\section{Atos de Pesquisa em Educação - ISSN 1809-0354 \\ Blumenau, v.14, n.2, supl.1, p.670-692, out./nov. 2019 \\ DOI: http://dx.doi.org/10.7867/1809-0354.2019v14n2s1p670-692}

fundamenta el análisis teórico y el recorrido metodológico del trabajo. Se toma como documentos de análisis textos políticos de alcance nacional, documentos de alcance local y las memorias de diversos sujetos involucrados en el proceso. Se concluye que las marcas impresas en el diseño de Guarderías de la LBA aún hoy presentan fuertes repercusiones en la educación infantil nacional, sometiendo a las instituciones de educación infantil la idea de proveedores de favor a los más necesitados.

Palabras-clave: Guardería. Educación infantil. Infancia. Legión Brasileña de Asistencia.

\section{CONSIDERAÇÕES INICIAIS}

A análise do papel desempenhado pela Legião Brasileira de Assistência - LBA no atendimento à infância no Brasil, durante o final da década de 1970 e o decorrer da década de 1980, é o foco do presente artigo. Nesse sentido, esta escrita propõese evidenciar as funções desempenhadas pela LBA nacionalmente e os desdobramentos de suas ações, especialmente através do projeto nacional de Creches Casulo em um contexto específico: Francisco Beltrão/PR.

Este texto trata-se de um recorte de uma investigação que propõe visibilizar processos de constituição da infância na sociedade. A pesquisa assume a História Cultural como base epistemológica que fundamenta a análise teórica e o percurso metodológico do trabalho (PESAVENTO, 2008a, 2008b; BURKE, 2008). Nesta perspectiva as representações possibilitam a análise do fenômeno de construção social da realidade, através de sinais, imagens, discursos e práticas sociais que qualificam o mundo e orientam o olhar e a percepção sobre essa realidade (PESAVENTO, 2008b).

A história define as condições e as possibilidades da presença da infância na sociedade, em cada tempo e lugar, condicionando a existência de um conjunto de elementos que delimitam os contornos de "condições específicas de existência para as crianças em cada espaço-tempo" (SARMENTO, 2011, p. 584). Nesse sentido, este trabalho tem em vista ampliar o conhecimento sobre a infância e a educação infantil em nossa sociedade a partir do olhar sobre o papel desempenhado pela LBA, uma entidade que atuou significativamente no Brasil, no campo da assistência à infância. 


\section{Atos de Pesquisa em Educação - ISSN 1809-0354 \\ Blumenau, v.14, n.2, supl.1, p.670-692, out./nov. 2019 \\ DOI: http://dx.doi.org/10.7867/1809-0354.2019v14n2s1p670-692}

Textos políticos de abrangência nacional e as memórias de diversos sujeitos envolvidos no processo ${ }^{1}$, são tomados nesta escrita como documentos e servem para refletir e compreender o passado. As memórias têm constituído documentos singulares e decisivos que têm contribuído para o conhecimento de elementos da educação de outras épocas históricas (NUNES, 2002/2003).

Assim, a metodologia da história oral possibilitou utilizar-se da memória, a fim de aprofundar a compreensão sobre aspectos do contexto no qual se desenvolve a pesquisa (GRAZZIOTIN; ALMEIDA, 2012). O procedimento de busca, seleção, composição das memórias daqueles que estiveram presentes no período de criação das primeiras creches, em conjunto com outros documentos escritos e de imagem, permitiu identificar práticas e representações que compuseram o processo de institucionalização da infância nas creches em Francisco Beltrão.

A primeira parte do texto enfatiza a LBA e seu projeto nacional de creches, 0 projeto Casulo, com enfoque na caracterização da entidade e do projeto, bem como o contexto nacional à época, explicitando os delineamentos da assistência à pobreza no Brasil no final da década de 1970 e na década de 1980. A seguir, o texto aborda como se estabeleceu a assistência à infância e a educação infantil em Francisco Beltrão/PR, sinalizando o papel de destaque da Associação de Proteção à Maternidade e à Infância - APMI - desde a independência política do município e durante o processo de criação das primeiras creches, juntamente com a LBA.

\section{A LEGIÃO BRASILEIRA DE ASSISTÊNCIA E SEU PROJETO NACIONAL DE CRECHES}

A LBA foi criada em 1942, pela ação da primeira-dama Darcy Vargas, com a finalidade de prestar serviços de assistência social, tendo em vista proteger a

\footnotetext{
${ }^{1}$ Foram realizadas entrevistas com diferentes profissionais que atuaram na gestão municipal e nas creches durante a década de 1980, período em que foram criadas as primeiras instituições públicas de atendimento à infância no contexto investigado. A composição do conjunto de sujeitos da pesquisa foi se estabelecendo por nomes indicados em documentos e pelas indicações dos próprios entrevistados. Assim compõe o conjunto de sujeitos da pesquisa: Duas Presidentes da APMI; 1 Supervisora Pedagógica da Secretaria de Assistência Social; 1 Coordenador da divisão de desenvolvimento da comunidade e divisão social - DAS; 1 Assistente Social; 1 Supervisora Técnica da LBA; 20 profissionais que atuaram nas creches como Monitoras; Diretoras; Coordenadoras Pedagógicas, Serviços Gerais.
} 


\section{Atos de Pesquisa em Educação - ISSN 1809-0354 \\ Blumenau, v.14, n.2, supl.1, p.670-692, out./nov. 2019 \\ DOI: http://dx.doi.org/10.7867/1809-0354.2019v14n2s1p670-692}

maternidade e a infância com ênfase na família dos convocados para a II Guerra Mundial. A partir de 1946, volta-se exclusivamente à maternidade e à infância, constituindo-se em órgão de consulta do Estado brasileiro. A instituição passa a efetuar suas ações através dos centros de proteção à criança e à mãe, as APMI Associação de Proteção à Maternidade e à Infância - que passam a ser difundidos por todo Brasil (KRAMER, 1987). Campos, Rosemberg e Ferreira (1995) destacam sua vocação para abranger todo o território nacional, sendo considerada a primeira instituição de assistência social de âmbito nacional.

Esse órgão teve como proposta desempenhar uma "missão legionária de assistência à pobreza brasileira". Assim, sua imagem junto à população era de "mãe da pobreza, lar do carente, socorro dos aflitos", conforme destacam Sposati e Falcão (1989, p. 09). A LBA, durante sua longa trajetória de atuação, teve a mulher e a criança como destinatários importantes de suas ações. As autoras assinalam que seu caráter é fundado na filantropia ${ }^{2}$, sua atuação se consolidou através de parcerias, estabelecendo uma forma de ação de âmbito nacional demarcada pela interação público e privado. Acumulou diversos papéis e perfis. Inicialmente foram as primeirasdamas as protagonistas de sua história, substituídas pela figura dos técnicos na medida em que a instituição se transforma em órgão governamental. Da mesma forma, "as alianças com voluntários e órgãos filantrópicos para a prestação de serviços, vão sendo substituídas pelas relações com prefeituras e organizações populares" (SPOSATI; FALCÃO, 1989, p. 11). Importante salientar a especificidade da entidade, "a expressão da parceria entre o Estado, o empresariado e o voluntariado feminino, para entender a pobreza", o que "constitui uma estratégia institucional extremamente particular, que mais expressou um pacto populista entre Estado e sociedade civil" (SPOSATI; FALCÃO, 1989, p. 16).

No período em que foi criado o projeto Casulo, o órgão integrava o Sistema Nacional de Previdência e Assistência Social - SIMPAS do Ministério da Previdência e Assistência Social -, e tinha como função:

Prestação de assistência social à população carente, mediante programas de desenvolvimento social e de atendimento às pessoas, independentemente da

\footnotetext{
2 Filantropia é "a organização racional da assistência em substituição à caridade, prática dominada pela emoção, por sentimento de simpatia e piedade", em que 0 atendimento à população em situação de pobreza deixa de ser uma ação de pessoas de "boa vontade" (KUHLMANN JR, 1999, p.61).
} 


\section{Atos de Pesquisa em Educação - ISSN 1809-0354 \\ Blumenau, v.14, n.2, supl.1, p.670-692, out./nov. 2019 \\ DOI: http://dx.doi.org/10.7867/1809-0354.2019v14n2s1p670-692}

vinculação destas a outras entidades do SINPAS; execução de serviços de assistência complementar não prestados diretamente pelo INPS e pelo INAMPS aos seus beneficiários (BRASIL, 1977, p. 2) ${ }^{3}$.

Campos, Rosemberg e Ferreira (1995, p. 31) apontam que a entidade, "a partir de 1977, passa a atuar de forma sistemática na área da creche - com a criação do Projeto Casulo". O Projeto Casulo expande-se intensamente tornando-se seu principal projeto. Conforme Nunes et al. (2011, p. 24): "o Projeto Casulo foi a ação mais expressiva da LBA, tanto pelo número de crianças atendidas, quanto por sua capilaridade no território nacional". O Projeto de Creches caracterizava-se por ser um programa de âmbito nacional; atuação através de convênios, repassando verbas para as prefeituras ou instituições privadas; atendimento à população de baixa renda; jornada diária de atendimento de 4 ou 8 horas; creches instaladas em equipamentos simples, com aproveitamento de espaços ociosos da comunidade e, concepção preventiva e compensatória de atendimento infantil (ROSEMBERG, 2006; CAMPOS, ROSEMBERG, FERREIRA, 1995).

Nunes et al. (2011) avaliam que o projeto teria tido o papel de difundir o componente educação, tendo em vista que até então predominava em relação às creches o aspecto assistencial e de saúde. Assim, "as creches da Assistência Social passaram a ter, senão na prática efetiva, pelo menos na concepção e na orientação metodológica, a função "guardiã" e a função "pedagógica"” (NUNES et al., 2011, p. 24). Essa preocupação foi expressa no livro de orientação prática, intitulado "Vamos fazer uma creche", editado em 1981 pelo Ministério da Previdência e Assistência Social (MPAS), ao qual a LBA estava vinculada no período que explicitava as ações educacionais a serem desenvolvidas.

Efetivamente o Projeto Casulo foi concebido para ser um projeto de ampla abrangência. Em entrevista concedida ao Centro de Pesquisa e Documentação de História Contemporânea do Brasil - CPDOC da Fundação Getúlio Vargas ${ }^{4}$-, Luiz Fernando da Silva Pinto, Engenheiro Econômico, presidente da LBA no período entre 1976 a 1979, explica que assumiu o cargo, a convite do Ministro da Previdência Social

\footnotetext{
${ }^{3}$ Documento A Previdência e a Assistência Social no Brasil - 1974/1977 obtido através de consulta ao banco de dados do Portal Fundação Carlos Chagas: História da Educação e da Infância.

${ }^{4} \mathrm{~A}$ entrevista foi realizada na vigência do convênio entre CPDOC-FGV (Fundação Getúlio Vargas) e Ministério da Previdência e Assistência Social - Secretaria de Estado de Assistência Social.
} 


\title{
Atos de Pesquisa em Educação - ISSN 1809-0354 \\ Blumenau, v.14, n.2, supl.1, p.670-692, out./nov. 2019 \\ DOI: http://dx.doi.org/10.7867/1809-0354.2019v14n2s1p670-692
}

à época, Luiz Gonzaga do Nascimento e Silva", que "decidiu dar um choque estratégico na LBA. Ele resolveu dar uma última chance à LBA: ou fechava ou continuava" (PINTO, 2002, p. 02-03). Acentua que, quando foi, para LBA logo percebeu que ela não possuía um projeto de massa, ou seja, um projeto com amplo atendimento e com custo padrão. E no sentido de atender a um desafio proposto pelo ministro foi desenvolvido o projeto Creche Casulo. Ele avalia que o projeto cresceu rapidamente e destaca:

\begin{abstract}
Assinala que na ocasião em que o Ministro da Previdência Nascimento e Silva ia anunciar, na TV - rede Globo, o programa houve um engano e ao invés de 60 creches para o país, foram anunciadas 600 e com isso a LBA teve que realizar as 600 creches pois a procura foi muito expressiva, "ele [o Ministro] recebeu telegramas e telex do Brasil inteiro pedindo creche" (PINTO, 2002, p. 15).
\end{abstract}

Pinto (2002, p. 03) explica que esse projeto significou uma "libertação com relação à regulamentação das creches", pois até então haviam padrões técnicos estabelecidos por regulamentação nacional que implicavam em custos e critérios que tornariam "impossível" fazer um projeto de massa. Ele assinala que, na ocasião, ponderou que "isso não é a realidade brasileira! Então vamos fazer a creche pobre. Uma creche com o pé no chão, pé no barro". E a partir daí a opção foi efetuar um projeto novo, com novos padrões, ao que ele explica que "a Unidade Casulo podia ser um anexo de uma escola, podia ser uma vila abandonada, podia ser um vagão ferroviário. $\mathrm{O}$ importante era que fosse muito asseado, quer dizer, que atendesse a todos os requisitos de saúde".

O entrevistado pelo CPDOC ainda acentua que a ideia não foi sua criação, esse projeto nasceu no Movimento Brasileiro de Alfabetização - Mobral $^{6}$, onde também havia sido colocada uma pessoa qualificada na área econômica para cuidar da alfabetização. Desse modo, ele explica que fez "exatamente uma transposição e uma série de ajustes", portanto, foi no Mobral que nasceu a ideia de que se poderia "trabalhar junto às populações carentes com projeto de massa" (PINTO, 2002, p. 05). O Mobral foi o responsável, durante a década de 1980, por estabelecer os indicativos da educação das crianças menores de 6 anos no Brasil, atuando no processo de

\footnotetext{
5 Gestão do Presidente Ernesto Geisel - Regime Militar Brasileiro (1974 a 1979).

${ }^{6}$ Programa do governo federal iniciado em 1971 e extinto em 1985. Seu objetivo era a erradicação do analfabetismo no Brasil (ARCE, 2008).
} 


\section{Atos de Pesquisa em Educação - ISSN 1809-0354 \\ Blumenau, v.14, n.2, supl.1, p.670-692, out./nov. 2019 \\ DOI: http://dx.doi.org/10.7867/1809-0354.2019v14n2s1p670-692}

expansão desse atendimento em todo o território nacional. Arce (2008, p. 380) destaca que "a utilização de recursos da comunidade e o voluntarismo, marcas do trabalho do MOBRAL com a educação de adultos, acabaram por encontrar na educação infantil um terreno fértil para a cristalização das mesmas".

Luiz Fernando Pinto explica que com o desenvolvimento do projeto perceberam que era possível a realização de projetos com grande velocidade de resposta, que "poderia ser realmente um caminho para abreviar a luta contra a pobreza" (PINTO, 2002, p. 06). Ele avalia que na troca de governo ${ }^{7}$ o projeto enfraqueceu porque não havia o mesmo interesse nesse formato de investimento, pois ele define que "o gasto em assistência social é um investimento" (p. 08). No âmbito da previdência, onde estava alocada a LBA, isso era entendido como "desvio filosófico" e ele expõe que sua análise na época foi de que "ia demorar muitos anos [...] para as pessoas entenderem a importância da alavancagem social através de projetos de massa" (PINTO, 2002, p. 06). Destaca ainda, que o projeto estava dando certo e obteve uma grande aceitação da população, dos políticos, independente do partido. Foi um projeto que chegou a atender dois milhões de crianças. Pinto (2002, p. 13) define o projeto casulo como "usina extraordinária de sorrisos", com uma resposta muito rápida no âmbito do bem-estar das crianças, "de ver as crianças engordarem".

Nesse contexto, a creche configura-se como uma instituição, a baixo custo, que visa suprir as carências de todas as ordens das crianças pobres de 0 a 6 anos, onde se expressa a fragmentação de ações institucionais, e com atribuições salvadoras no enfrentamento das condições de pobreza do território brasileiro.

O Brasil, comprometido com a execução de tal projeto, lança, através do MEC, - Programa Nacional de Educação Pré-Escolar, em 1981, estabelecendo uma proposta de educação de massa no âmbito da educação pré-escolar. Contudo, apesar do MEC ter formulado, a proposta de educação de massa foram o MOBRAL a LBA, através do Projeto Casulo, lançado em 1977, que efetivamente implantaram o programa (ARCE, 2008). MOBRAL e LBA foram responsáveis ou contribuíram com a publicação de três documentos que estabeleciam definições para as creches: em 1980 o Instituto de Assistência ao Menor lança o documento Programa Creche; em 1981, o Ministério da Previdência e Assistência Social (MPAS), ao qual a LBA estava

\footnotetext{
7 Troca do governo do presidente Ernesto Geisel para o governo do presidente João Figueiredo.
} 


\section{Atos de Pesquisa em Educação - ISSN 1809-0354 \\ Blumenau, v.14, n.2, supl.1, p.670-692, out./nov. 2019 \\ DOI: http://dx.doi.org/10.7867/1809-0354.2019v14n2s1p670-692}

vinculada, edita livro de orientação prática, o Vamos fazer uma creche?. O projeto coordenado pelo Mobral, Primeiro a criança, produziu as Orientações básicas para $o$ atendimento em creche (1988). Esses documentos, seguiram a mesma linha de proposição de ações assistencial-compensatórias a baixo custo. Retratam a tendência da educação pré-escolar da década de 1980 período em que pela necessidade de expansão das creches a rigorosidade cede lugar a propostas simplificadas de atendimento (VIEIRA, 1988).

O projeto de creches da LBA, foi um projeto de amplo desenvolvimento em âmbito nacional. Com isso, como destaca Pinto, "tinha creche em navio abandonado, tinha creche em vagão, tinha creche numa escola, tinha creche dentro de um clube". Ele acentua, na entrevista, que "Criança é pequenininho, cabe em qualquer lugar era uma graça" (PINTO, 2002, p. 18). De acordo com sua avaliação o período auge de funcionamento do projeto Casulo foi para ele o "momento de glória" no Brasil da "alavancagem e projetos de massa, combinados com o voluntariado" (PINTO, 2002, p. 18). Salienta que, excetuando o período da gestão da LBA realizada por Darci Vargas, em seu período inicial em 1943, o ano de 1978, como o desenvolvimento do projeto Casulo teria sido o maior momento da assistência social no Brasil. Para ele teria sido possível mudar o país, pois foi um importante investimento "que dava resultado rápido e alavancava a família, alfabetizava a família, profissionalizava a família" (PINTO, 2002, p. 23), defende que através da creche se conseguia envolver e trabalhar com toda a família, pois a creche servia de "isca" para chamar a família.

Em função dos parcos recursos repassados pela LBA, a realidade das creches espalhadas pelo país era precária. No relatório do Encontro Nacional de Creches foram localizadas informações sobre o desenvolvimento do projeto da LBA em outros contextos de âmbito nacional. Em Ribeirão Preto/SP, a representante analisa que havia uma sobrecarga de trabalho das funcionárias das creches, baixa remuneração e grande número de crianças por adulto (Encontro Nacional de creches. V1. 1981.p. 26) ${ }^{8}$.

Luiz Fernando Pinto explica que se tratava de um projeto simples em sua execução, as diretorias regionais da LBA mapeavam "as obras comunitárias mais

\footnotetext{
${ }^{8}$ Documento obtido através de consulta ao banco de dados do Portal Fundação Carlos Chagas: História da Educação e da Infância.
} 


\section{Atos de Pesquisa em Educação - ISSN 1809-0354 \\ Blumenau, v.14, n.2, supl.1, p.670-692, out./nov. 2019 \\ DOI: http://dx.doi.org/10.7867/1809-0354.2019v14n2s1p670-692}

sérias de uma determinada região" (PINTO, 2002, p. 13), estabeleciam o convênio com estas e o monitoramento e acompanhamento da execução do projeto. Assim, a LBA fornecia um valor per capita e a obra social comparecia com as instalações e equipamentos que poderiam ser bastante simples, bem como os recursos humanos. Em função disso, efetivamente as entidades conveniadas procuravam desenvolver o projeto com o mínimo de recursos. Nesse formato de estabelecimento de parcerias, as creches eram administradas pelas obras sociais conveniadas e a LBA supervisionava a execução a partir dos encargos mínimos estipulados por ela e repassados às instituições conveniadas.

O conjunto de indicativos analisados deixa explícito que ao falarmos de creche na década de 1980 é necessário entendê-la como um equipamento social voltado para a assistência à infância pobre que teve suas raízes nas primeiras iniciativas de atendimento aos bebês no Brasil. Essa instituição, a partir do final de década de 1970, ganha outros contornos, caracterizando-se pela simplificação dos recursos.

É preciso entender o papel desempenhado pela LBA no Brasil e, de forma mais ampla, a política nacional voltada à primeira infância estabelecida entre as décadas de 1970 e 1980, como ações alinhadas às indicações de organismos multilaterais aos países periféricos, que prescreviam modelos de educação de massa ditos "não formais" a baixo investimento público (ROSEMBERG, 2002, 2003a, 2003b; CAMPOS, 2008; VIEIRA, 1988). Nesse período o Fundo das Nações Unidas para a Infância UNICEF - e a Organização das Nações Unidas para a Educação, Ciência e Cultura UNESCO - ajudaram propalar em países pobres discursos em torno da ideia de que a expansão da educação infantil constitui uma via para combater a pobreza onde, através dela, resolver-se-iam os problemas de desnutrição infantil e melhorar-se-ia o desempenho do ensino fundamental, e que isso deveria ser realizado através de “modelos que minimizem investimentos públicos" (ROSEMBERG, 2003b, p.180). Assim,

[...] para reduzir os investimentos públicos, os programas devem apoiar-se nos recursos da comunidade, criando programas denominados "não formais", "alternativos", "não institucionais" isto é, espaços, materiais, equipamentos e recursos humanos disponíveis na "comunidade", mesmo quando não tenham sido concluídos ou preparados para esta faixa etária e para seus objetivos (ROSEMBERG, 2003b, p.180). 


\section{Atos de Pesquisa em Educação - ISSN 1809-0354 \\ Blumenau, v.14, n.2, supl.1, p.670-692, out./nov. 2019 \\ DOI: http://dx.doi.org/10.7867/1809-0354.2019v14n2s1p670-692}

Nesse contexto a creche passa a configurar-se como um "equipamento necessário para a nova ordem social", constituindo-se um modelo inicialmente apontado como de caráter emergencial, pautado pela racionalização dos recursos e trabalho comunitário. Vieira (1988, p. 05) esclarece que a "justificativa era a mesma para os países do terceiro mundo: os Estados são pobres para investir em educação, saúde, etc. Devem optar por soluções simplificadas, de baixo custo e de alta rentabilidade social". Essas são as marcas decalcadas pela LBA e MOBRAL em sintonia com os discursos dos organismos multilaterais que estabeleceram a pauta das ações de países periféricos, como o Brasil.

\section{OS DESDOBRAMENTOS DO PROJETO DE CRECHES DA LBA: AÇÕES DA APMI E LBA EM FRANCISCO BELTRÃO/PR}

O histórico do atendimento à infância em Francisco Beltrão é marcado pela criação da Associação de Proteção à Maternidade e a Infância Dr. Haroldo Beltrão APMI. Criada no mesmo ano de independência política do município, em 1952, pelo médico Rubens da Silva Martins ${ }^{9}$, juntamente com senhoras da comunidade. Conforme narra Martins (1986, p.113):

Movido pelo desejo de prestar às crianças desamparadas e às gestantes de baixa renda, carentes de recursos de toda ordem, uma ampla cobertura assistencial, fundei, em três de março de 1952, com a participação dos membros da comunidade marrecoana a Associação de Proteção à Maternidade e à Infância "Dr. Haroldo Beltrão", conforme ata registrada no Cartório de Títulos e Documentos do 1‥ Ofício, em Curitiba.

No excerto acima fica explícito a motivação para a criação desta instituição que captou recursos junto ao Departamento Estadual da Criança para a construção de um Posto de Puericultura (MARTINS, 1986). Em âmbito nacional, o Departamento Nacional da Criança foi criado em 1940 e extinto em 1969, vinculado ao Ministério da Educação e Saúde, tratou-se do órgão de coordenação de todas as ações relativas à proteção à maternidade, à infância e à adolescência (BRASIL, 1940). No estado do Paraná, o Departamento Estadual da Criança - DECr -, foi o órgão estadual com a mesma finalidade, criado em 13 de maio de 1947 pelo Decreto-Lei $n^{\circ}$ 615,

\footnotetext{
${ }^{9}$ Foi o primeiro prefeito de Francisco Beltrão, exercendo o mandato de 1953 a 1956. Desempenhou outras funções de destaque no município e foi sócio/fundador da APMI.
} 


\section{Atos de Pesquisa em Educação - ISSN 1809-0354 \\ Blumenau, v.14, n.2, supl.1, p.670-692, out./nov. 2019 \\ DOI: http://dx.doi.org/10.7867/1809-0354.2019v14n2s1p670-692}

regulamentado e aprovado pelo Governador Moisés Lupion, em 20 de junho do mesmo ano através do Decreto 2.517. O DECr atuou junto aos municípios através das APMls.

Os Postos de Puericultura foram uma das frentes de ação do programa de governo do DECr, na década de 1950, no combate à mortalidade infantil, compondo um conjunto de ações de assistência ao binômio mãe-filho que incluía lactários, maternidades, creches, bancos de leite humano, postos volantes, hospitais de crianças e artesanatos (ALVES, 2015). Em Francisco Beltrão o posto oferecia atendimento gratuito, medicamentos, enxovais, vacinas, leite em pó e "orientação útil e carinhosa" às crianças, gestantes e puérperas, sob os cuidados da Dra. Diva Sanson Martins, primeira-dama.

A presença da primeira-dama à frente de uma importante iniciativa de assistência à população é um aspecto que merece destaque, pois esta é questão propalada pela própria assistência social no país, naquele período, e que tem impactos até os dias atuais. O primeiro damismo brasileiro teve suas bases estabelecidas na Era Vargas. Darcy Vargas desempenhou papel de destaque:

Em larga proporção, ela mobilizou outras mulheres e vários segmentos da sociedade para o trabalho voluntário e assistencial até a constituição da primeira e mais importante instituição de cunho assistencial, a LBAS que foram projetadas as bases para o primeiro damismo brasileiro. Darcy Vargas [...] teve uma representatividade na história das mulheres e na história da assistência social (SILVA, 2009, p. 134).

A APMI, como uma associação propalada pela própria LBA, seguia as referências estabelecidas nacionalmente. Contudo, ao mesmo tempo, essa primeiradama possuía credenciais profissionais que autorizava sua presença, para além da presença de primeira-dama, como profissional na área da saúde. Questão que se constituiu como tendência nacional, tem sua expressão no município investigado, onde por longo período, as primeiras damas estiveram à frente das ações no campo da assistência social, e a APMI representou no município importante papel nesta área, coordenando ações do setor de assistência social.

Em relação ao papel desempenhado pela APMI no município, Martins (1986, p. 114) acentua que "o atendimento prestado à população infantil não se restringia à distribuição dos recursos mencionados", juntamente "momentos de lazer e de felicidade faziam parte da programação do Posto que, nos dias festivos - Dia da 


\section{Atos de Pesquisa em Educação - ISSN 1809-0354 \\ Blumenau, v.14, n.2, supl.1, p.670-692, out./nov. 2019 \\ DOI: http://dx.doi.org/10.7867/1809-0354.2019v14n2s1p670-692}

Pátria, Dia da Criança, Natal e outras datas comemorativas - promovia encontros". A entidade realizou até a década de 1990 a função de "espaço cultural de encontro de mães e crianças" (Ata APMI 18 de dezembro de 1971, fl. 18).

Na narrativa de Martins (1986) destaca-se as expressões com que se refere às ações da APMI, que seriam a "boa causa" em prol dos "menos favorecidos da sorte". Desse modo, junto com a formação de Francisco Beltrão, nasce a assistência à infância pobre do município, a ser presidida pela primeira-dama, com a conotação marcante da época, como favor aos necessitados, que se propaga pelas décadas seguintes. Desse modo, se estabelece a finalidade da APMI: "dar assistência à saúde, às mães e às crianças pobres da cidade" (Ata APMI 22 de julho de 1972, fl. 22).

A assistência à saúde esteve na pauta das ações da APMI, com grande ênfase até a década de 1980. A APMI atuava juntamente com a Secretaria de Saúde e Assistência, bem como, sendo a responsável por captar recursos para execução de vários projetos, sobressaindo-se mesmo como a centralizadora e coordenadora de diversas ações. Gradativamente as ações da APMI centram-se mais na assistência, convergindo com a separação da Secretaria de Assistência e Saúde (organizada nas divisões de saúde e assistência); nas Secretarias de Assistência Social e Secretaria de Saúde.

A partir do ano de 1980, começam a ser criadas as creches públicas municipais, através da APMI e Departamento de Assistência Social - DAS. A primeira creche do município tem início junto ao Centro Social Urbano ${ }^{10}$, para atender crianças de 0 a 6 anos (FRANCISCO BELTRÃO, 2007). Lourdes ${ }^{11}$, presidente da APMI no período da criação de primeira creche, explica que no início de sua gestão foram reestruturados e ampliados os Clubes de Mães e a partir desse trabalho com as mães, expõe Lourdes:

\footnotetext{
10 Decreto no 75.922/1975 criou o Programa Nacional de Centros Sociais Urbanos - CSU - que previa a instalação destes centros com a finalidade promover a integração social das populações circunvizinhas aos equipamentos e por meio de seu envolvimento em atividades comunitárias, nas áreas de educação e cultura, saúde e nutrição, desporto, trabalho, previdência e assistência social, recreação e lazer. Os CSUs foram implantados em diversos municípios brasileiros no período entre 1975 e 1984 (BORBA, 1991).

11 Entrevista concedida em 2013. Lourdes Arruda foi Presidente da APMI; nos períodos de 1977 a 1983 e 1993 a 1996, na condição de 1‥ Dama, também foi membro da diretoria em diversos outros períodos e assumiu como secretária da Assistência Social em 2001, estando à frente dessa secretaria, bem como da APMI até 2012.
} 


\title{
Atos de Pesquisa em Educação - ISSN 1809-0354 \\ Blumenau, v.14, n.2, supl.1, p.670-692, out./nov. 2019 \\ DOI: http://dx.doi.org/10.7867/1809-0354.2019v14n2s1p670-692
}

"[...] a gente começou a ver a dificuldade das mães, precisavam trabalhar. Não tinham com quem deixar seus filhos, e nos próprios cursos que elas vinham, a gente tinha uma sala com bercinho, colchão no chão e tal, pra elas trazerem as crianças e poder participar" (Lourdes, presidente da APMI).

Desse modo, a criação da primeira creche delineia-se em função dessa necessidade, acentuada em sua gestão na APMI. Consta em ata que, em audiência com o governador Jaime Canet Junior, seria solicitado a instalação de uma creche, no entanto, esta, somente foi efetivada em 1980, com recursos da LBA (ATA APMI, 24 de junho de 1977). Lourdes explica que o programa da LBA possibilitava que com poucos recursos uma creche fosse instalada e afirma que a LBA foi fundamental para a criação da primeira creche no município:

\begin{abstract}
"A LBA junto conosco, era uma equipe muito boa, e eles não se importavam, o tanto que você tivesse um espaço adequado, não precisava ser prédios... desde que você pudesse estar fazendo essa proteção". [...] "não se teria condições. Não, porque nós tínhamos uma pobreza muito grande, e nós tínhamos necessidade de habitação também. Então com esse recurso daí o município já podia pensar em outras coisas" (Lourdes, presidente da APMI).
\end{abstract}

A entrevistada assinala o papel da LBA em diversas frentes: "todo o benefício que a LBA tinha sabe, de documentação a vontade que a nossa população necessitava documentação, óculos, próteses", sinalizando que o município foi destinatário de diversos dos projetos desse órgão. Os serviços oferecidos pela instituição abrangiam, conforme Sposati e Falcão (1989), campos de ação envolvendo quatro grupos populacionais: a assistência social geral para famílias e pessoas com problemas de subsistência - os necessitados; assistência a grupos especiais, portadores de deficiência e idosos; as ações voltadas à população economicamente ativa com pouca ou nenhuma inserção no mercado de trabalho; e, por fim, a assistência materno-infantil que envolvia diversos programas como o projeto casulo (creches), apoio nutricional, ações básicas de saúde, banco de leite materno, assistência social complementar, colônia de férias a crianças em idade escolar. Avaliando a contribuição da LBA, Lourdes assinala que "pra nós foi um tempo muito bom [...]. E depois daquela época houve programas pra substituir, mas como a LBA, não. [...] pra nós, Francisco Beltrão, a LBA foi muito boa". 


\title{
Atos de Pesquisa em Educação - ISSN 1809-0354 \\ Blumenau, v.14, n.2, supl.1, p.670-692, out./nov. 2019 \\ DOI: http://dx.doi.org/10.7867/1809-0354.2019v14n2s1p670-692
}

A assistente social Zélia ${ }^{12}$, que atuou no DAS, refere-se à vinculação entre LBA e APMI:

"Ela [LBA] repassava um percapta, conforme o número de crianças. E aí precisava existir uma entidade civil, uma sociedade não pública, aí a figura das APMls, que faziam também trabalho com gestantes, com idosos, com grupos vulneráveis na época conforme a realidade. Mas principalmente aí tinha muito a questão da mãe da criança" (Zélia, Assistente Social).

Dessa forma, desde a criação da primeira creche em 1980 até a extinção da LBA em 2005, a APMI foi responsável por firmar o convênio com a LBA e receber os recursos para a manutenção das creches do município. Entretanto, desde o início, os demais custos para a manutenção das creches foram subsidiados pela administração pública municipal e com a contribuição da APMI que, além dos recursos da LBA, arrecadava doações para serem destinadas às creches. Desse modo, em Francisco Beltrão/PR apesar dos convênios terem sido celebrados com a APMI e esta ser responsável ou corresponsável pela gestão das creches, a administração pública municipal fornecia o espaço físico, remunerava as funcionárias, realizava o transporte das crianças e ainda responsabilizava-se por outros custos como os de manutenção, aquisição de equipamentos, também parte dos custos com alimentação. Conforme João ${ }^{13}$, um dos coordenadores do DAS, o valor per capita repassado pela LBA era insuficiente para os custos relativos aos itens que ela subsidiava. Ele assinala que:

\begin{abstract}
"Os recursos que vinham da LBA davam pra $50 \%$ dos custos das creches, porque você era obrigado a gastar $70 \%$ em alimentação, $20 \%$ com material de higiene limpeza e $10 \%$ com itens escolares. Era assim dividido. Os $20 \%$ de material de higiene e limpeza nunca foram suficientes, nunca foram, e nem a parte a pedagógica e não tinha recurso para equipamentos" (João, coordenador do DAS).
\end{abstract}

Com isso, a prefeitura municipal, além de contribuir com os demais custos que estavam fora dos itens do convênio, necessitava complementar esses itens. Além disso, nem sempre os convênios eram renovados a tempo de receber em dia o repasse da LBA, conforme anotado em reunião da APMI:

João de Andrades, responsável pela alimentação das crianças das creches fez uma exposição da situação financeira, sendo que a percapta não supre

\footnotetext{
${ }^{12}$ Entrevista concedida em 2013. Zélia Maria de Matos Lopes, atuou como Assistente Social do Departamento de Assistência Social, no período de 1984 a 1988.

${ }^{13}$ Entrevista concedida em 2013. João Maria de Andrades foi Coordenador da divisão de desenvolvimento da comunidade e divisão social do Departamento de Assistência Social no período de 1983 a 1988.
} 


\section{Atos de Pesquisa em Educação - ISSN 1809-0354 \\ Blumenau, v.14, n.2, supl.1, p.670-692, out./nov. 2019 \\ DOI: http://dx.doi.org/10.7867/1809-0354.2019v14n2s1p670-692}

as necessidade. Após discutido profundamente o assunto ficou decidido para se fazer uma tomada de preços nos mercados da cidade, para que se pudesse manter essa alimentação até que assine o próximo convênio, que este ano tem tendência a atrasar (Ata no 001/85, 07 de fevereiro de 1985, fl 35-36).

O projeto de creches da LBA tinha como principal característica estruturar-se sobre bases materiais e humanas oferecidas pela comunidade. Tratava-se de um projeto de massa que estabelecia um custo fixo por criança, independente do contexto ao qual se destinava, cabendo às entidades conveniadas colocar o programa em prática com os recursos oferecidos pela entidade e com aquilo que poderiam complementar. No documento elaborado pela LBA, Vamos Fazer uma creche $?^{14}$, publicado pelo Ministério da Previdência e Assistência Social, em 1981, durante o período em que a entidade estava vinculada a este ministério, nas orientações para a execução do programa, conforme destaca Tatagiba (2011, p.153), fica explícito que:

Pretendendo garantir um lugar para o maior número de crianças possível e com baixos custos operacionais, a equipe diretora do Casulo ratificava o interesse em atingir as seguintes metas:

- utilizar a capacidade ociosa de entidades sociais

- criar novas vagas nas obras já existentes

- ampliar o espaço em escola ou outra instituição comunitária, fazendo um "puxadinho" onde funcionaria a creche contando com a infraestrutura (cozinha, sanitários etc.) já existente (MPAS, 1981, p. 3).

A APMI atuava em conjunto com a administração municipal, na administração das creches. A respeito disso, João assinala que durante o período em que foi responsável pelas creches no DAS (1983 a 1988), os recursos para a criação e manutenção das creches municipais eram provenientes tanto da arrecadação própria do município, como dos recursos da APMI, captados através do convênio com a LBA.

"A nível de recursos do município era tudo interno e aquele que a APMI repassava que vinha do órgão federal. E aí passou a ter algumas contribuições da iniciativa privada que eram esporádicas" (João, coordenador do DAS).

Foram localizados três tipos de convênio, celebrados com a APMI e com a Prefeitura Municipal. Os convênios permitem identificar que os recursos desta entidade destinavam-se às despesas (que incluía alimentação, materiais de higiene/limpeza), e havia outras modalidades que destinavam-se à reforma e

\footnotetext{
${ }^{14}$ Trata-se de documento com poucos exemplares, não foi localizado para consulta. Aqui é utilizada a citação de Tatagiba (2001) que realizou análise do material.
} 


\section{Atos de Pesquisa em Educação - ISSN 1809-0354 \\ Blumenau, v.14, n.2, supl.1, p.670-692, out./nov. 2019 \\ DOI: http://dx.doi.org/10.7867/1809-0354.2019v14n2s1p670-692}

construção de creches, assim como à manutenção, através da aquisição de equipamentos. Dentre os extratos de convênio localizados no Diário Oficial da União - DOU ${ }^{15}$ (o Quadro 1 apresenta dois extratos de convênio a título de exemplo) -, identificou-se que os convênios que tinham por objeto atendimento de crianças e manutenção foram celebrados com a APMI e os convênios para construção/expansão de creche foram celebrados diretamente com a prefeitura municipal de Francisco Beltrão.

A LBA, através de suas superintendências regionais, efetuava supervisão das creches. As entrevistadas fazem referência a esse aspecto, indicando que havia visitas periódicas de representação da entidade. Além disso, cada creche elaborava relatórios referentes ao seu trabalho, encaminhados regularmente à LBA.

Quadro 1: Extratos de contrato/convênio entre LBA e Francisco Beltrão (APMI e Prefeitura Municipal)

\begin{tabular}{|c|c|c|}
\hline $\begin{array}{l}\text { Identificação } \\
\text { do convênio }\end{array}$ & Extrato do Diário Oficial da União & Fonte \\
\hline $\begin{array}{l}\text { Extrato contrato } \\
\text { entre LBA e } \\
\text { APMI - } 1987\end{array}$ & 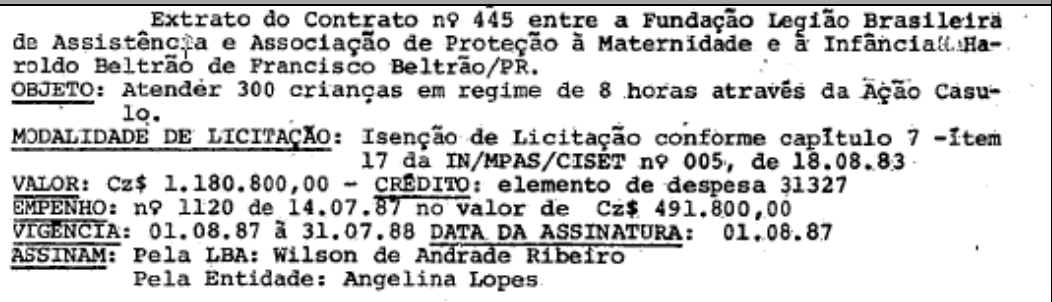 & $\begin{array}{l}\text { DOU. } 27 \\
\text { de agosto } \\
\text { de } 1987 . \\
\text { Seção } 1 \text {, } \\
\text { p. } 61 .\end{array}$ \\
\hline $\begin{array}{l}\text { Extrato convênio } \\
\text { entre LBA e } \\
\text { Prefeitura } \\
\text { Municipal de } \\
\text { Francisco } \\
\text { Beltrão para } \\
\text { Creche } \\
\text { expansão } \\
\text { (Construção) - } \\
1989\end{array}$ & 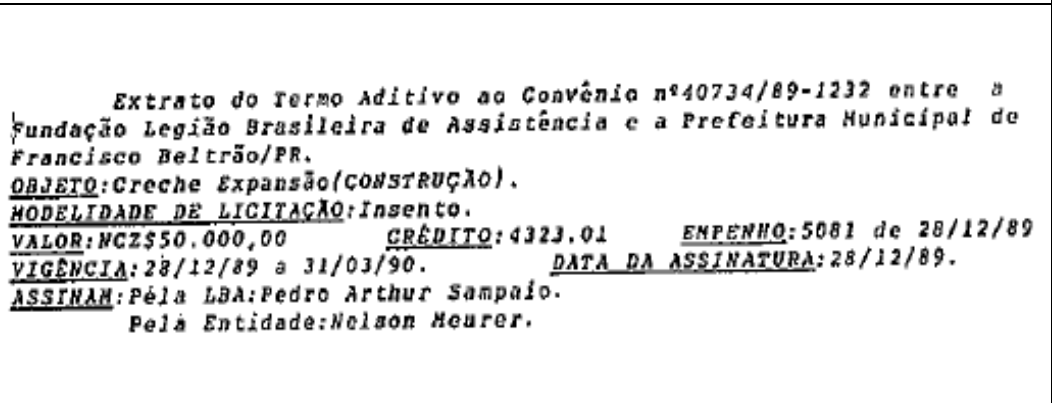 & $\begin{array}{l}\text { DOU. } 01 \\
\text { de } \\
\text { fevereiro } \\
\text { de } 1990 . \\
\text { Seção } 1 \\
\text { p. } 99 .\end{array}$ \\
\hline
\end{tabular}

Fonte: Elaborado pelo autor a partir de consulta ao Diário Oficial da União.

15 Utilizando-se a palavra-chave Francisco Beltrão em pesquisa no Diário Oficial da União foram localizados extratos referentes ao período de 1987 a 1992. 


\section{Atos de Pesquisa em Educação - ISSN 1809-0354 \\ Blumenau, v.14, n.2, supl.1, p.670-692, out./nov. 2019 \\ DOI: http://dx.doi.org/10.7867/1809-0354.2019v14n2s1p670-692}

Juraci $^{16}$, Salete ${ }^{17}$ e Zeneide ${ }^{18}$, que atuaram como coordenadoras de creche, fazem referência às visitas de supervisão que eram efetuadas pela equipe da LBA diretamente nas creches.

"Eram visitas frequentes, onde revisavam os cadernos de presença das crianças para confirmar se estavam de acordo com os relatórios" (Salete, coordenadora de creche).

"[...] a LBA vinha visitar nós, contava quantos alunos tinha, conferia na chamada, era 60 era 60 , porque eles mandavam não sei quanto por criança, a prefeitura complementava, mas era muito pouquinho, mas não tinha outros recursos" (Zeneide, coordenadora de creche).

A esse respeito, Margarete $^{19}$, supervisora da LBA, identifica que a LBA realizava o acompanhamento do trabalho nas creches, o qual ela identifica que se centrava em constatar, prioritariamente, "se o dinheiro estava sendo aplicado com as crianças e se as crianças estavam sendo bem tratadas". Ela explica que através dos relatórios e das visitas às instituições efetuavam o controle do número de crianças atendidas no intuito de verificar se a entidade conveniada estava cumprindo a meta de atendimento que era estabelecida no ato da assinatura do convênio. Além disso, a supervisão tinha o propósito de analisar a qualidade do atendimento, conforme exposto por ela:

"[...] vinha o nome da criança, com a idade, e quando trocava uma criança eles também nos informavam, por exemplo, saiu Joãozinho e entrou Maria no lugar, porque tinha que fechar aquelas metas dos convênios. [...] a gente se preocupava com o que na época, ver se o espaço físico era adequado, se a alimentação era boa, se as crianças estavam bem tratadas, nesse sentido mais do cuidar mesmo, sabe" (Margarete, supervisora técnica da LBA).

Além da supervisão, as atividades da equipe da LBA abrangiam o repasse de algumas definições gerais sobre o trabalho a ser realizado com as crianças, através de treinamentos, "diretrizes de como cuidar a criança", nas palavras de João.

A entidade também realizava a supervisão das atividades desenvolvidas na creche:

\footnotetext{
${ }^{16}$ Entrevista concedida em 2013. Juraci Ribeiro da Rosa atuou de 1981 a 1985 como professora e coordenadora de Creche.

17 Entrevista concedida em 2013. Maria Salete Hellmann atuou de 1983 a 1994 nos cargos de Auxiliar Administrativo - Coordenação de Creche e Monitora de creche.

18 Entrevista concedida em 2013. Zeneide Pazzeto iniciou em 1982 e trabalha até os dias atuais na Prefeitura Municipal de Francisco Beltrão, tendo atuado nos cargos de Auxiliar Administrativo Coordenação de Creche, Monitora de creche e professora de Educação Infantil.

${ }^{19}$ Entrevista concedida em 2013. Margarete Misturini atuou como Supervisora Técnica da LBA, da Superintendência Estadual da LBA, no período de 1992 a 1994.
} 


\title{
Atos de Pesquisa em Educação - ISSN 1809-0354 \\ Blumenau, v.14, n.2, supl.1, p.670-692, out./nov. 2019 \\ DOI: http://dx.doi.org/10.7867/1809-0354.2019v14n2s1p670-692
}

\begin{abstract}
"Elas cobravam o pedagógico, porque eu fazia relatório trimestral e tinha umas perguntas que fazia sobre a pedagogia, eu colocava o pedagógico que era feito, mas mais era pros grandes né. A gente colocava que era mais recreação, brincadeira supervisionada, brincadeira orientada, essas coisas assim que era mais feito né. Aí quando veio o pré, logo veio o pré aí eu colocava mais sobre o pré, escrevia sobre a pré-escola. E os pequenos a gente não colocava muito, mais recreação e brinquedo, brincadeiras. A LBA cobrava" (Zeneide, coordenadora de creche).
\end{abstract}

Neste conjunto de normativas estabelecidas pela LBA estavam incluídas aquelas que diziam respeito às condições socioeconômicas das famílias a serem atendidas. Desse modo, eram seguidas suas orientações quanto às prioridades para ingresso na creche. Inicialmente a creche priorizava as famílias com renda mais baixa ou mesmo sem renda, esse período parece ir até a segunda metade da década de 1980. João assinala que

"[...] as mães que não trabalhavam ou que a família não tivesse renda, o que acontecia a gente conseguia a vaga pra criança e trabalhava com a família com a preparação pro mercado de trabalho. Era isso, nós dávamos curso de formação, de qualificação para as mães, para os pais" (João, coordenador do DAS).

Ao longo do período analisado, do início da década de 1980 até meados de 1990, podemos identificar uma mudança em relação às condições socioeconômicas das famílias que frequentam as creches municipais. Num primeiro momento, vão para a creche aquelas de famílias em situação de extrema pobreza, que necessitam da creche até mesmo para proverem a alimentação. Ao final da década de 1980 essa situação começa sofrer uma modificação, pois impera a normativa de somente manter nas creches filhos de mães trabalhadoras.

As entrevistadas referem-se a uma mudança que elas perceberam em relação aos sujeitos frequentadores das creches. Nesse processo, famílias as quais as mães não trabalhavam passaram a ficar fora das creches, pois a prioridade passou para a criança da mãe com vínculo de trabalho e que por isso necessitava deixar as crianças numa instituição. Nesse período a creche se estabelece mais efetivamente como um direito da mulher trabalhadora. Acerca disso,

Dona Leci [Presidente da APMI] também falou aos pais a respeito da exigência da LBA de que as mães devem mandar para a coordenadora a declaração que a mãe trabalha, porque não serão aceitas nas creches crianças de mães que não trabalham fora (Ata $n^{\circ} 004 / 89,25$ de fevereiro de 1989, fl. 23-24). 


\title{
Atos de Pesquisa em Educação - ISSN 1809-0354 \\ Blumenau, v.14, n.2, supl.1, p.670-692, out./nov. 2019 \\ DOI: http://dx.doi.org/10.7867/1809-0354.2019v14n2s1p670-692
}

Em outra ata consta que: "falou ainda [D. Leci] que todos nós devemos zelar por este bem que é a creche na qual nós e a LBA estamos oferecendo às mães que trabalham fora" (Ata nº 006/89, 04 de março de 1989, fl. 25-26).

Zeneide faz referência a esse procedimento seletivo do qual ela participou como coordenadora de creche:

\begin{abstract}
"Eles vinham, a assistente social e a auxiliar da assistente social, acompanhar o fichário e ver o salário dos pais. Era uma seleção muito supervisionada. A gente não podia pegar... tinha que pegar o comprovante da mãe, tinha que investigar onde a mãe trabalhava, vê quanto ganhava, depois que a mãe fazia matrícula tinha que ter até visitas, a gente fazia muito visitas".
\end{abstract}

As Creches Casulo desde seu início efetivamente foram:

Criadas para proporcionar às mães carentes, do quarto extrato da população, condições de exercerem atividades lucrativas que elevem sua renda familiar. Os menores atendidos, de $\mathrm{O}$ a 6 anos, em sistema de semi-internato, recebem cuidados higiênicos, médicos, odontológicos e nutricionais (BRASIL, 1977, p.7).

Proporcionar às famílias em situação de pobreza condições para o trabalho remunerado da mulher desde o início da criação da primeira creche no município esteve na justificativa de criação dessas instituições. Ao longo do período as prioridades foram diferentes. No início da década a prioridade eram as famílias em condições extremas de pobreza, e a partir do final de década passa a preponderar a ideia de atendimento às famílias de menores condições, aliada a ideia de direito da mãe trabalhadora.

Diante disso, pode-se assinalar que a rede municipal de educação infantil se estabelece sobre as bases de uma proposta emergencial de atendimento à pobreza fundamentada na ideia de baixo custo e na operacionalização através da precariedade de recursos físicos e humanos. O projeto nacional de expansão de creches, conduzido pela LBA, estabelecido nestes moldes, foi apropriado e transformado no projeto municipal de creches de Francisco Beltrão. Este não se restringiu às características do projeto nacional, contudo, é inegável que as mesmas imprimiram suas fortes marcas nas instituições públicas de atendimento à infância beltronense.

\section{CONSIDERAÇÕES FINAIS}




\section{Atos de Pesquisa em Educação - ISSN 1809-0354 \\ Blumenau, v.14, n.2, supl.1, p.670-692, out./nov. 2019 \\ DOI: http://dx.doi.org/10.7867/1809-0354.2019v14n2s1p670-692}

As marcas impressas pelo projeto de creches da LBA ainda hoje apresentam fortes repercussões na educação infantil nacional. A entidade foi responsável por uma política residual (NUNES; CORSINO, 2011), em que o Estado atende uma parcela da população, focalizando os grupos marcados pela exclusão ou pobreza. Esse projeto brasileiro, imprimiu fortes marcas na cultura da creche, delineando caracteres da infância e da educação da infância no Brasil.

A análise do contexto específico - Francisco Beltrão - possibilita apreender o modo pelo qual as políticas nacionais irão imprimir marcas e delinear concepções e práticas de educação da criança pequena. A ideia de pobreza da criança se estabelece como uma concepção que afeta profundamente os modos de educação na creche, e invisibiliza outros modos de viver a infância, que também estão presentes neste lugar. A precariedade de recursos se sobrepõe ao atendimento das especificidades das crianças e ao desenvolvimento de suas potencialidades.

A educação infantil pública ainda não se estabeleceu como um efetivo direito da criança, permanece como um "direito de papel" (FÜLLGRAF, 2002). Assim, a desvinculação da ideia das instituições públicas de educação infantil como prestadoras de favor aos pobres está longe de ser consolidada. É preciso, ainda, a defesa da educação infantil como direito da criança e da família, como espaços de educação e cuidado, numa perspectiva universalista, assentada na ideia do direito universal (NUNES; CORSINO, 2011). Impasses e conquistas compõe o contexto nacional, desenhando um quadro de permanências e mudanças no campo do atendimento institucional à primeira infância.

O trabalho histórico possibilita visualizar, conforme indica Fischer (2005, p. 237), "transformações se processando, em ritmos diferenciados [...] movimentos, em diferentes níveis, processando-se ao longo do tempo". Não se vê rupturas, mas encontra-se "a história como um todo andando em compasso lento, demonstrando de quando em quando possíveis irrupções" (FISCHER, 2005, p. 237).

\section{CAROLINE MACHADO CORTELINI CONCEIÇÃO}

Possui graduação em Pedagogia pela Universidade Federal de Santa Maria (1999), mestrado em Educação pela Universidade Federal de Santa Maria (2004) e doutorado pela Universidade do Vale do Rio dos Sinos (2014). Realizou doutorado sanduíche em Estudos da Criança, na Universidade do Minho - Braga/Portugal (Bolsa CAPES 


\section{Atos de Pesquisa em Educação - ISSN 1809-0354 \\ Blumenau, v.14, n.2, supl.1, p.670-692, out./nov. 2019 \\ DOI: http://dx.doi.org/10.7867/1809-0354.2019v14n2s1p670-692}

PDSE). Professora adjunta da Universidade Estadual do Oeste do Paraná - Campus Francisco Beltrão. Tem experiência na área de Educação, com ênfase em Ensino Superior, atuando principalmente nos seguintes temas: educação infantil, infância e formação de professores. É membro do Grupo de Pesquisa Educação, Crianças e Infâncias - GPECI.

\section{REFERÊNCIAS}

ALVES, J. M. Assistência aos pobres em Londrina: 1940/1980. Londrina/PR: Eduel, 2015.

ARCE, A. O Mobral e a educação de crianças menores de seis anos durante o regime militar: em defesa do trabalho voluntário. Cadernos CEDES, Campinas, vol. 28, n. 76, p. 379-403, set./dez., 2008. Disponível em :

$<$ http://www.scielo.br/scielo.php?pid=S0101-

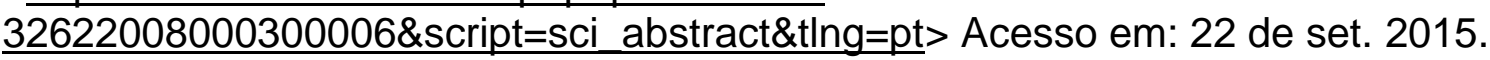

APMI. Livro Ata 1971. Ata APMI 18 de dezembro de 1971.

APMI. Livro Ata 1972. Ata APMI 22 de julho de 1972.

APMI. Livro Ata 1977. Ata APMI 24 de junho de 1977.

BRASIL. Decreto-lei no 2.024, de 17 de fevereiro de 1940. Fixa as bases da organização da proteção à maternidade, à infância e à adolescência em todo o País. Presidência da República. Rio de Janeiro, 1940.

BRASIL. A Previdência e a Assistência Social no Brasil - 1974/1977. Ministério da Previdência e Assistência Social, 1977.

BORBA, S. V. A produção de equipamentos urbanos como alternativa de política social - o programa nacional de Centros Sociais Urbanos. Ensaios FEE. Porto Alegre, Vol 12, N 2, p. $403-421,1991$.

BURKE, P. O que é História Cultural? Tradução: Sergio Góes de Paula. Rio de Janeiro: Zahar, 2008.

CAMPOS, M. M. Educar crianças pequenas: em busca de um novo perfil de professor. Retratos da Escola. Brasília, v. 2, p. 121-131, 2008. Disponível em: < file:///C:/Users/User/Downloads/130-557-1-PB.pdf> Acesso em: 15 de dez. 2016.

CAMPOS, M.M.; ROSEMBERG, F.; FERREIRA, I. M. Creches e pré-escolas no Brasil. São Paulo: Cortez,1995.

ENCONTRO NACIONAL DE CRECHES. Dossiê. São Paulo. V1. 1981. 


\section{Atos de Pesquisa em Educação - ISSN 1809-0354 \\ Blumenau, v.14, n.2, supl.1, p.670-692, out./nov. 2019 \\ DOI: http://dx.doi.org/10.7867/1809-0354.2019v14n2s1p670-692}

FISCHER, B. T. D. Professoras: Histórias e discursos de um passado presente. Pelotas: Seiva Publicações, 2005.

FLÁVIO, L. C. Memória(s) e território: elementos para o entendimento da constituição de Francisco Beltrão-PR. Tese (Doutorado). Universidade Estadual Paulista “Júlio Mesquita Filho", Presidente Prudente/SP, 2011.

FRANCISCO BELTRÃO. Plano Municipal de Educação. Francisco Beltrão:

Prefeitura Municipal/Secretaria Municipal de Educação, Cultura e Esporte, 2007.

FRANCO, M. E. W. Educação e infância: uma cumplicidade. In: REDIN, Euclides; REDIN, Marita M.; MÜLLER, Fernanda (Orgs.). Infâncias - Cidades e escolas amigas das crianças. Porto Alegre, mediação, 2007.

FÜLLGRAF, J. Direito das crianças à educação infantil: um direito de papel. In: Reunião Anual da ANPED, 25, 2002. Caxambu. Anais. Caxambu: Anped, 2002, v. 1.

GRAZZIOTIN; L. S. S.; ALMEIDA, D. B. Romagem do tempo e recantos da memória: reflexões metodológicas sobre história oral. São Leopoldo: Oikos, 2012.

KRAMER, S. A política do pré-escolar no Brasil: A arte do disfarce. São Paulo: Cortez, 1987.

KULHMANN JR. M. Educação Infantil e Currículo. In FARIA. A.L.G, PALHARES. M. S. Educação infantil pós LDB: rumos e desafios. São Paulo: Autores Associados, 1999.

MARTINS, R. Entre jagunços e posseiros. Curitiba: Associação Marrecas do Bem Estar ao Menor, 1986.

NUNES, C. Memória e História da Educação: entre práticas e representações. Revista Educação em Foco. UFJF.v.7, n. 2, set 2002/fev 2003.

NUNES, M. F. R. [et al.] Educação Infantil no Brasil: primeira etapa da educação básica. Brasília: UNESCO, 2011.

NUNES, M. F. R.; CORSINO, Patrícia. Políticas públicas universalistas e residualistas: os desafios da educação infantil. In: ROCHA, E. A. C.; KRAMER, S. Educação Infantil: enfoques em diálogo. São Paulo: Papirus, 2011.

PINTO, L. F. S. Luiz Fernando Pinto II (depoimento, 2001). Rio de Janeiro, CPDOC/MINISTÉRIO DA PREVIDÊNCIA E ASSISTÊNCIA SOCIAL - SECRETARIA DE ESTADO DE ASSISTÊNCIA SOCIAL, 2002.

PESAVENTO, S. J. História Cultural: caminhos de um desafio contemporâneo. In: PESAVENTO, S. J.; SANTOS, N. M. W.; ROSSINI, M. S. (orgs.). Narrativas, imagens e práticas sociais: percursos em história cultural. Porto Alegre, RS: Asterisco, 2008a. 
PESAVENTO, S. J. História \& História Cultural. Belo Horizonte: Autêntica, 2008b.

ROSEMBERG, F. Organizações multilaterais, estado e políticas de educação infantil. Cadernos de Pesquisa, São Paulo, n. 115, 6/ 32, março, 2002. Disponível em: $<$ http://www.scielo.br/scielo.php?pid=S0100-

$15742002000100002 \&$ script=sci abstract\&tlng=pt $>$ Acesso em: 12 de abr. 2010.

ROSEMBERG, F. Panorama da Educação Infantil brasileira contemporânea. Simpósio Educação Infantil: construindo o presente. Anais. - Brasília: UNESCO Brasil, 2003a.

ROSEMBERG, F. Sísifo e a educação infantil brasileira. Revista Pro-Posições, vol. 14, N. 1 (40), Jan/abr. 2003b. Disponível em:

$<$ http://www.scielo.br/scielo.php?pid=S0100-

$15742002000100002 \&$ script=sci abstract\&tIng=pt $>$ Acesso em: 14 de nov. 2017.

ROSEMBERG, F. A LBA, o Projeto Casulo e a Doutrina de Segurança Nacional. In: FREITAS, M. F. História social da infância no Brasil. 6ª Ed. São Paulo: Cortez, 2006.

SARMENTO, M. J. A reinvenção do ofício de criança e de aluno. Atos de pesquisa em educação, Blumenau, v. 6, n. 3, p. 581-602, set./dez. 2011. Disponível em: $<$ http://proxy.furb.br/ojs/index.php/atosdepesquisa/article/view/2819> Acesso em: 25 de mar. 2014.

SILVA, L. S. Mulheres em cena: roupagens do primeiro damismo na assistência social. Dissertação (Mestrado). Pontifícia Universidade Católica do Rio de Janeiro. Rio de Janeiro, 2009.

SPOSATI, A.; FALCÃO, M. C. LBA: identidade e efetividade das ações no enfrentamento da pobreza brasileira. São Paulo: EDUC, 1989.

TATAGIBA, A.P. Percursos de uma luta urgente: a educação infantil como dever do Estado SER Social, Brasília, v. 13, n. 29, p. 146-171, jul./dez. 2011. Disponível em: $<$ http://periodicos.unb.br/index.php/SER Social/article/view/6357> Aceso em: 25 de mai. 2017.

VIEIRA, L. M. F. Mal necessário: creches no Departamento Nacional da Criança (1940-1970). Cadernos de Pesquisa, São Paulo, n. 67, Nov., 1988. 